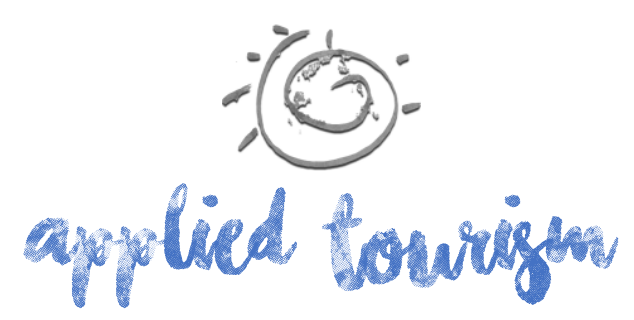

Volume 2, número 2, 2017, 43-55

\title{
CONSIDERAÇÕES ACERCA DA HOSPITALIDADE RELIGIOSA NO ÂMBITO DA IGREJA CATÓLICA: alguns estudos de caso
}

\author{
Jean Guilherme Florentino Corrales \\ Acadêmico do Curso de Bacharelado em Hotelaria \\ Universidade Federal do Rio Grande - FURG \\ chiefinspectorclouseau@gmail.com \\ Enilda Maria Fangueiro Pereira \\ Acadêmico do Curso de Bacharelado em Hotelaria \\ Universidade Federal do Rio Grande - FURG \\ enildamfpereira@hotmail.com \\ Francieli Boaria \\ Mestre em Turismo e Hotelaria \\ Universidade Federal do Rio Grande - FURG \\ franboaria@gmail.com
}

Recebido: 28 de junho, 2017

Aprovado: 04 de setembro, 2016

\section{RESUMO}

O presente artigo pretende explicitar como a hospitalidade é conceituada dentro da doutrina católica, bem como entender o exercício daquela pelos adeptos do catolicismo através da contemplação de alguns estudos de caso. Trata-se de pesquisa exploratória à qual se subsidia de fontes bibliográficas e acessos a páginas web, utilizando método indutivo para a discussão de dados angariados. A análise dos estudos de caso permitiu concluir que, em termos gerais, a hospitalidade é praticada pelos católicos, muito embora as fontes sobre o tema sejam ainda escassas e que o termo "hospitalidade" como tal seja de difícil verificação na literatura disponível.

Palavras-chaves: Hospitalidade. Hospitalidade religiosa. Catolicismo. Solidariedade. Salvação. 


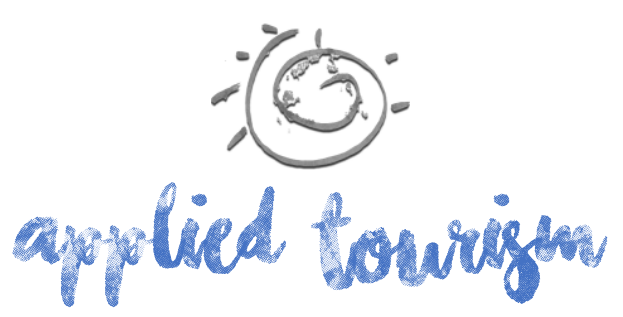

Volume 2, número 2, 2017, 43-55

\section{INTRODUÇÃO}

Cuida o presente trabalho de verificar a conceituação de hospitalidade em âmbito religioso, mais especificamente na religião católica, e as relações existentes entre este conceito e a prática a ser adotada por seus adeptos quanto ao tema. Torna-se palpitante esta discussão na medida em que a acolhida, a guarida e a comensalidade encontram eco nos ensinamentos de Jesus Cristo, chegando inclusive a imporem-se estas condutas como ocasião - ou condição - salvífica.

Durkheim (p. 32, 1996) define religião como "um sistema solidário de crenças e práticas relativas a coisas sagradas, isto é, separadas, proibidas, crenças e práticas que reúnem numa mesma comunidade moral, chamada igreja, todos aqueles que a ela aderem" ressaltando a importância da temática para o ser humano e justificando este estudo. Elucida-se que a religiosidade é uma faculdade de pessoas que se interessam por coisas sagradas, na exteriorização de credo por meio de liturgia, doutrina e protocolo próprios.

Grinover (p. 32, 2006) afirma que "a hospitalidade supõe a acolhida; é uma das leis superiores da humanidade, é uma lei universal. Acolher é permitir, sob certas condições, a inclusão do outro no próprio espaço". A Bíblia Sagrada auxilia a descobrir o significado religioso da hospitalidade, que não é considerada apenas um gesto humanitário, mas um aspecto do mandamento cristão. Exemplifica-se que acolher o hóspede e o forasteiro, significa acolher Cristo, que se iguala ao excluído: "Era forasteiro e me hospedaste" (Bíblia, Mateus, 25,35).

A comensalidade encontra-se intrinsecamente inserida neste cenário, em que a acolhida, a convivência, o respeito e a tolerância culminam com a convivência à mesa. A hospitalidade abre a porta e acolhe. A convivência permite a troca de experiências, o sentar juntos, o intercâmbio. Uma é tão fundamental quanto à outra, pois se estendem e se complementam (Boff, 2006). 


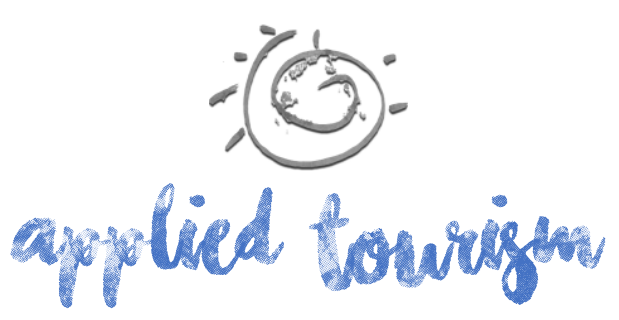

Volume 2, número 2, 2017, 43-55

\section{REFERENCIAL TEÓRICO}

O ponto de partida da presente pesquisa consiste em verificar qual o papel da hospitalidade à luz da doutrina cristã. No Evangelho segundo Mateus, capítulo 25, versículos 31 a 46, Jesus descreve a seus discípulos como será o juízo final, tendo todos os seres humanos diante de si e separados de acordo com suas obras em dois grandes grupos, um de cada lado:

(...) Então dirá o rei aos que estiverem à sua direita: "Vinde, benditos de meu Pai, recebei por herança o Reino preparado para vós desde a fundação do mundo. Pois tive fome e me destes de comer. Tive sede e me destes de beber. Era forasteiro e me recolhestes. Estive nu e me vestistes, doente e me visitastes, preso e viestes ver-me." (...) "Em verdade vos digo: cada vez que o fizestes a um desses meus irmãos mais pequeninos, a mim o fizestes." Em seguida, dirá aos que estiverem à sua esquerda: "Apartai-vos de mim, malditos, para o fogo eterno preparado para o diabo e para os seus anjos. Pois tive fome e não me destes de comer. Tive sede e não me destes de beber. Fui forasteiro e não me recolhestes. Estive nu e não me vestistes, doente e preso, e não me visitastes." (...) "Em verdade vos digo: todas as vezes que o deixastes de fazer a um desses pequeninos, foi a mim que o deixastes de fazer." E irão estes para o castigo eterno, enquanto os justos irão para a vida eterna.

Percebe-se, desde logo, a hospitalidade com uma função eminentemente salvífica, "(...) todo homem se encontra desde já na presença do Filho do Homem, e é por ele interrogado.” (Mien, 2000, p. 232) “(...) É no outro, portanto, que encontramos a máxima densidade da presença de Deus. (...) Tudo passa pelo outro, fora dele não há salvação. O inferno não é o outro, como afirmou Jean Paul Sartre, mas o caminho para o céu." (Boff, 2005, p. 149).

Rodrigues (2015) elucida a máxima desta passagem bíblica, dizendo que

(...) o critério de salvação não são as doutrinas e os dogmas, nem as liturgias e os ritos, mas o amor sem limites que reconhece nos diminuídos a "grandeza" de Deus e não lhes deixa faltar o necessário: comida, bebida, segurança, abrigo, alívio, cuidado, amparo, companhia, etc. Sem isso a religião carece de "carne" e de "relevância" aos seres humanos de cada tempo (ibidem, p. 73). 


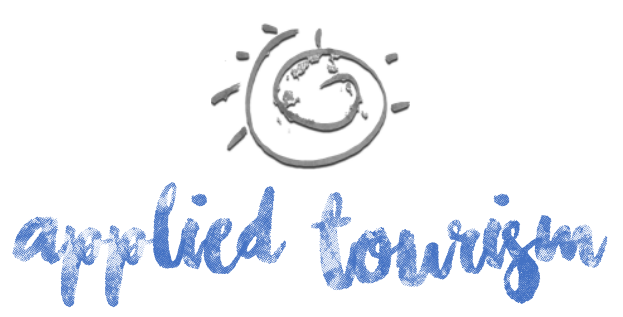

Volume 2, número 2, 2017, 43-55

Lubich (2000), importante pensadora cristã, sinaliza este "ser o Amor" de modo concreto a partir da seguinte ótica:

O amor nos insere em Deus, e Deus é o Amor. Mas o Amor, que é Deus, é luz e com a luz vemos se o modo como nos aproximamos e servimos o irmão está em conformidade com o Coração de Deus, está como o irmão gostaria, como ele sonharia se tivesse ao seu lado não nós, mas Jesus (p. 42-43, 2000).

Araújo (1994) explica que este amor não é sentimento ou emoção, "(...) mas concreto e real, que alivia e partilha as dores e os sofrimentos da vida" (p. 56). Alude, ainda, que os "pequeninos" citados por Jesus são todos aqueles que mais necessitam e com os quais o próprio Cristo se identifica “(...) e mostra-nos que o Amor por Ele se expressa através da partilha dos sofrimentos dessas mesmas pessoas, do alívio de suas dores." (idem).

No que tange aos estudos científicos no tocante do tema hospitalidade e relacionando com os relatos bíblicos, Mauss (1974) acredita na hospitalidade como uma dádiva, confiando que o contato humano não se dá como contrato comercial, e sim uma relação social. Camargo (2004) expõe sobre a hospitalidade como um agrupamento de leis que ordena o ritual social e que não estão escritas em parte alguma, onde sua observância abrange da antiguidade à modernidade. Além de uma virtude, a hospitalidade é considerada uma disposição da alma, aberta e ilimitada, como um amor incondicional, corrobora Boff (2005).

A hospitalidade pode ser refletida na ação de acolher vista como espontânea, aludindo à caridade, que é dependente da vontade do outro, ou seja

Um ato voluntário que introduz um recém-chegado ou um estranho em uma comunidade ou um território, que o transforma em membro desta comunidade ou em habitante legítimo deste território e que, a este título, o autoriza a beneficiar-se de todas ou parte das prerrogativas que se relacionam com o seu novo status, definitivo ou provisório (Gouirand, p. 180, 1996).

De acordo com Gouirand (1996), o homem precisa do outro para sua sobrevivência, dandose assim o processo de acolhimento, concluindo que este é um processo natural e social. Camargo (2004) e Boff (2005) corroboram quando afirmam que acolhimento é um fato social. 


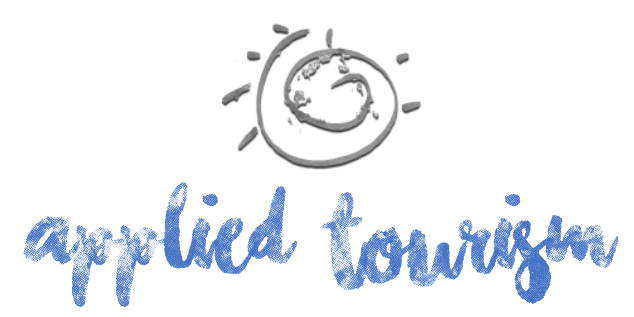

Volume 2, número 2, 2017, 43-55

Recordai-vos de que é necessário ter alguém que faça a comida do Senhor, e considerai-vos felizes por O servirdes como Marta. Vede que a verdadeira humildade reside em nossa disposição de nos contentar com aquilo que o Senhor quiser de nós e em nos considerar sempre indignas de ser tidas por servas suas. Se contemplar, ter oração mental, ter oração vocal, curar enfermos, servir nas coisas de casa e trabalhar - mesmo nas tarefas mais humildes - é servir ao Hóspede que vem ter conosco, ficando em nossa companhia, comendo conosco e conosco se recreando, que nos importa servi-Lo mais de uma maneira do que de outra? (Avila, p. 349, 2002).

Neste sentido, observa-se a hospitalidade enquanto o serviço ao outro, discutindo-se a ideia da hospitalidade humana citada por Mauss (1974) a qual é abordada como o ritual básico das relações humanas. Camargo (2004) traz esta discussão dentro das "leis não escritas de um ritual", traduzindo a citação anterior (Avila, 2002) na hospitalidade como dádiva; na dádiva enquanto sacrifício e interesse implícito; no dom de ser recebido; no ato de aceitar uma situação de inferioridade diante do doador; e, por fim, no dever de retribuição quando recebedor da hospitalidade.

A hospitalidade foi cultivada principalmente nas tradicionais peregrinações católicas, onde é possível identificála em seu âmbito mais primitivo - que remonta aos constantes deslocamentos realizados pelos apóstolos de Cristo para o anúncio do Evangelho -, como o Caminho de Santiago. Agrela (2013) relata o seguinte testemunho pessoal vivenciado no trecho entre as cidades espanholas de León e Hospital de Orbigo:

Sentir fome é algo comum no Caminho de Santiago. Embora a alimentação seja reforçada, com os tradicionais Menus do Peregrino, o esforço de caminhar sempre abre o apetite. Em 2007, ao passar por San Miguel del Camino, região próxima a Villadangos del Paramo, uma surpresa: no meio do caminho havia uma mesa. Sim, uma mesa repleta de frutas e biscoitos para os peregrinos, deixada por um morador do povoado chamado Agapito. Na segunda vez que realizei o roteiro, fui em busca de Agapito, que continuava firme e forte ajudando espontaneamente os peregrinos. Durante a conversa, perguntei-lhe: "Agapito, o que o leva a oferecer alimentos aos peregrinos todos os dias, há mais de dez anos, sem cobrar nada por isso?" Ele me respondeu, emocionado: "O coração!" (Agrela, p. 126, 2013). 


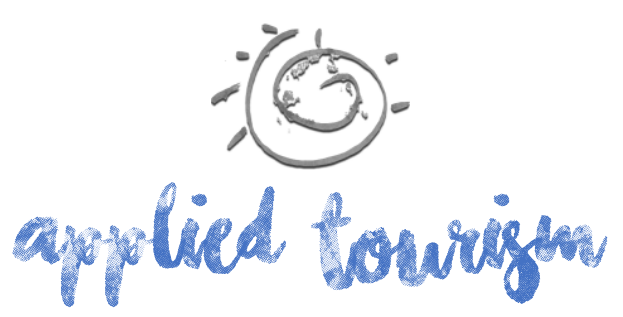

Volume 2, número 2, 2017, 43-55

Observa-se neste relato que a hospitalidade não está fundamentada num contrato de troca, como ensina a escola americana, e sim na hospitalidade como dar-receber-retribuir, debruçando-se na hospitalidade pública e doméstica, como explica a escola francesa (Mauss, 1974 \& Camargo, 2004). Em sua obra "O Ensaio Sobre a Dádiva" de Marcel Mauss, a tríade é estudada em sociedades antigas que demonstram que as trocas não tinham fim comercial, o que explica o sistema da dádiva onde a troca é desequilibrada. Assim, Agapito, como sugere a premissa fundamental da hospitalidade, não impõe condições, e sua retribuição é ficar feliz quando pode ser hospitaleiro com o outro.

Tal pressuposto também se faz presente em obras de ficção sobre o Caminho de Santiago, como o filme The Way, no qual o protagonista Tom Avery se vê em uma realidade completamente distinta do habitual e tendo uma experiência hospitaleira para além de relações comerciais.

Recentemente, tendo em vista um crescente aumento no número de peregrinos e dadas as dimensões que tem tomado a referida peregrinação, o município português de Conselho Municipal Albergaria-A-Velha (2017) promoveu um encontro especialmente dedicado à hospitalidade no Caminho de Santiago, com o fito de abordar a questão a partir de um ponto de vista turístico, visando principalmente a melhoria de condições dos albergues para peregrinos que trilham a chamada Via Lusitana, uma entre mais de dez rotas possíveis para atravessar rumo à cidade galega de Santiago de Compostela. Na maior parte do caminho os albergues são tarifados, porém, a preços módicos, objetivando cobrir custos mínimos de manutenção. Alguns deles, inclusive, deixam em aberto a contribuição a ser dada pelo peregrino (Agrela, 2013). Conclui-se que a matriz maussiana, neste caso, é considerada mais relevante mesmo que a troca esteja explícita, pois não se objetiva o lucro da versão comercial.

Nos documentos emitidos pelo Vaticano, a palavra "hospitalidade" não costuma ser referida como tal, sendo frequentemente englobada por termos macro como "solidariedade" ou "obras de misericórdia". A Doutrina Social da Igreja, apesar de reconhecer "falhas de muitos 


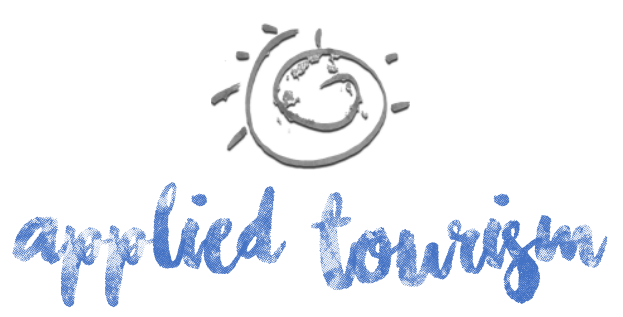

Volume 2, número 2, 2017, 43-55

de seus membros" (Pontifício Conselho Justiça e Paz, p. 110, 2005), ressalta a disposição institucional para o auxílio aos que mais necessitam. “(...) Mais que cumprir uma obra de misericórdia, saldamos um débito de justiça.' Os Padres Conciliares recomendam fortemente que se cumpra tal dever 'para que não se dê como caridade o que já é devido a título de justiça." (Pontifício Conselho Justiça e Paz, p. 110-111, 2005). Desta maneira, é possível vislumbrar a hospitalidade inserida neste contexto a partir de uma visão mais holística, considerando que as obras de misericórdia constituem um conjunto divisível, porém uniforme (Grün, 2009).

Castelli (2010) menciona o exemplo dos monges beneditinos que, a partir da fundação da Ordem de São Bento na Idade Média, passaram a dedicar-se à hospitalidade. Inicialmente pensada para os peregrinos em troca de contribuições espontâneas, terminou por acolher também mercadores e viajantes com finalidades recreativas. O capítulo 53 da Regra de São Bento estabelece as principais diretrizes norteadoras desta hospitalidade monástica, merecendo especial destaque a atenção total ao hóspede sem que o ambiente da abadia seja substancialmente alterado. Faz-se mister, portanto, o destacamento de pessoas específicas para o serviço aos hóspedes, bem como cômodos apartados de forma a permitir uma maior liberdade aos abrigados e a privacidade aos monges (Castelli, p. 53, 2010).

Ademais, os rituais de comensalidade verificados em outros capítulos da Regra “(...) foram precursores das boas maneiras à mesa na sociedade europeia, e, nesse sentido, os monges eram mais refinados do que os leigos, incluindo os nobres." (Franco apud Castelli, p. 54, 2010).

Ainda hoje, detecta-se este espírito vivo nas casas monásticas sob responsabilidade da Ordem ou de congregações derivadas desta. No centro do Rio de Janeiro-RJ (2017), a Ordem possui seu principal mosteiro no Brasil e que conta com a Casa de Emaús, um espaço para hospedagem composto por 28 apartamentos, refeitório, auditório climatizado e com equipamentos de som, salas de reunião, capela e jardins. Em seu site, expõe também algumas diretrizes de seu regulamento interno, tais como a inconveniência do uso de 


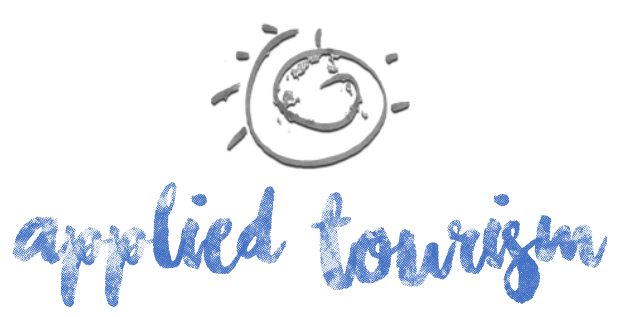

Volume 2, número 2, 2017, 43-55

roupas mais curtas - como short e bermuda -, e a importância de atender pontualmente os horários estabelecidos.

No Mosteiro da Transfiguração (2017), localizado em Mogi das Cruzes-SP e pertencente aos beneditinos camaldolenses, é oferecida a hospedagem com alimentação por um prazo habitual de uma semana por pessoa, pedindo-se do hóspede uma contribuição a ser ajustada com o irmão hospedeiro - monge destacado para a tarefa de receber os visitantes. Promovem cursos de formação espiritual e encontros de espiritualidade para os mais variados públicos-alvo.

O Mosteiro do Salvador (2017), composto por mulheres e localizado na Bahia, oferece também a possibilidade de receber visitantes interessados em conhecer a vida monástica. Sua hospedaria, chamada Casa Getsêmani, possui 20 suítes duplas, duas salas de conferência, refeitório e capela privativa. A igreja do mosteiro também está acessível e, do mesmo modo, a assistência das monjas às necessidades dos retiros individuais ou de grupo. Por sua vez, a Abadia da Ressurreição (2017), situada em Ponta Grossa-PR, enfatiza que possui uma capacidade limitada para receber hóspedes e que, por conta disto, é necessário reservar acomodações com antecedência. Além disso, destacam algumas das principais regras de seu regulamento interno, como o não recebimento de crianças devido à falta de estrutura adequada, a ausência de sinal de WiFi e a lembrança de que a hospedaria do mosteiro é um prolongamento do mesmo, não podendo por isso ser considerada uma "pousada" ou "hotel".

Outros mosteiros, como o de Brasília-DF (2017) e o de Campos do Jordão-SP (2017), não detalham as condições de hospedagem e limitam-se a oferecer os espaços mediante uma exibição de fotos e um texto onde é mencionada a possibilidade de serem feitos retiros usando a estrutura existente. 


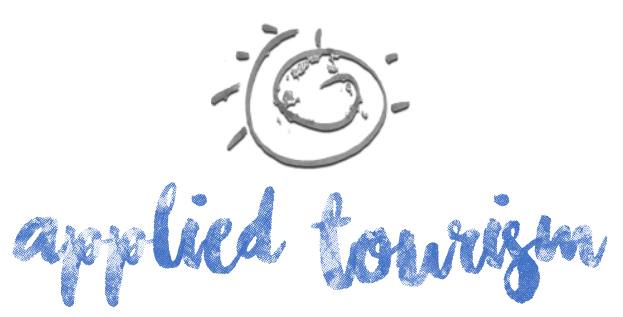

Volume 2, número 2, 2017, 43-55

Este estudo visou auxiliar na compreensão dos aspectos da hospitalidade na doutrina católica e elucidou que, em termos gerais, a hospitalidade é praticada pelos católicos. Buscando aproximar à realidade prática deste estudo, os pesquisadores pretendem continuar nesta temática ampliando a pesquisa no contexto atual, com aplicação de instrumentos em eventos religiosos.

\section{REFERÊNCIAS}

Abadia da Ressurreição. (2017). Hospedaria. Retrieved from http://abadiadaressurreicao.org/hospedaria

Agrela, D. (2013). Guia do Viajante do Caminho de Santiago. São Paulo: Évora.

Araujo, V. (1994). Jesus e o Uso dos Bens. Trad. João Batista Florentino. São Paulo: Cidade Nova.

Avila, S. T. de. (2002). Obras Completas. 2.ed. Trad. Adail Ubirajara Sobral et al. São Paulo: Loyola.

Biblia. (1994). Bíblia de Jerusalém. 3.ed. São Paulo: Paulus.

Boff, L. (2005). Virtudes para um outro mundo possível. Vol. I. Hospitalidade: direito e deveres de todos. Petrópolis: Vozes.

Boff, L. (2006). Virtudes para um outro mundo possivel. Vol. II. Convivência, respeito e tolerância. Petrópolis: Vozes.

Boff, L. (2008). A pesquisa em hospitalidade. Revista Hospitalidade. São Paulo, ano V, n. 2, pp. 15 51, jul.- dez.

Castelli, G. (2010). Hospitalidade: a inovação na gestão nas organizações prestadoras de serviços. São Paulo: Saraiva, 2010.

Camargo, L. O. L. (2004). Hospitalidade. São Paulo: Aleph.

Conselho Municipal de Albergaria-a-Velha. (2017). Programa do Encontro Albergaria 2017 Hospitalidade no Caminho de Santiago. Retrieved from http://www.cmalbergaria.pt/output_efile.aspx?id_file $=33470 \& i d \_o b j e c t=23315$

Christoffoli, A. (2007). Turismo e Religiosidade no Brasil: um estudo dos discursos da produção acadêmica brasileira. 145 f. Tese (Doutorado em Turismo e Hotelaria). Universidade do Vale do Itajaí, Balneário Camboriú.

Durkheim, É. (1996). As formas elementares da vida religiosa: o sistema totêmico na Austrália. Traduzido por: Paulo Neves. São Paulo: Martins Fontes, (Coleção Tópicos). Tradução de: Les formes elementares de la vie religieuse. 


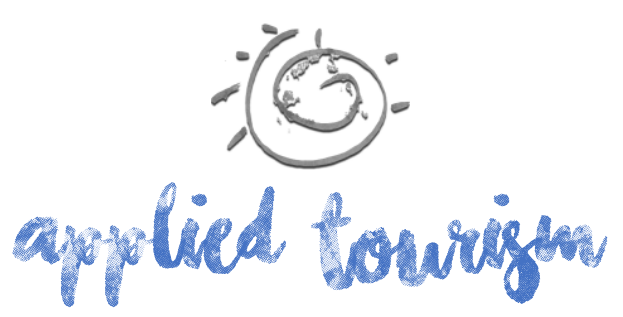

Volume 2, número 2, 2017, 43-55

Gouirand, P. (1996). Le Concept d' Accueil- Reconnaissance, Hospitalité et Matemage. Les Cabiers Espaces, France, n. 48, pp. 134-141.

Grinover, L. (2006). A hospitalidade urbana: acessibilidade, legibilidade e identidade. Revista Hospitalidade, São Paulo, ano III, n. 2, pp. 29-50, 2. sem.

Grün, A. (2009). Para que o Mundo se Transforme: As Sete Obras de Misericórdia. Trad. Ingeborg Scheible. Petrópolis: Vozes.

Lubich, C. (2000). Meditações. 11.ed. Trad. Equipe Editorial Cidade Nova. São Paulo: Cidade Nova.

Mauss, M. (1974). Ensaio sobre a dádiva. Forma e razão da troca nas sociedades arcaicas. In: Sociologia e Antropologia. v. II. São Paulo: Edusp.

Mien, A. (2000). Jesus, Mestre de Nazaré. 11. ed. Trad. Irami Bezerra da Silva. São Paulo: Cidade Nova.

Mosteiro da Transfiguração. (2017). Hospitalidade e Suas Formas. Retrieved from http://camaldolenses.com.br/hospitalidade.php?id=61

Mosteiro de São Bento de Brasília. (2017). Hospedaria. Retrieved from https://www.msbento.org.br/aboutus

Mosteiro de São Bento do Rio de Janeiro. (2017). Hospitalidade. Retrieved from http://www.osb.org.br/emaus.html

Mosteiro do Salvador. (2017). Hospedaria. Retrieved from http://mosteirodosalvador.org.br/msba/index.php/trabalhos/hospedaria

Mosteiro São João. (2017). Casa de Retiro Santa Scholastica. Retrieved from http://www.mosteirosaojoao.org.br/casa-de-retiro

Pontifício Conselho Justiça e Paz. (2005). Compêndio da Doutrina Social da Igreja. São Paulo: Paulinas.

Rodrigues, J. F. (2015). Alarga o Espaço da tua Tenda: Uma Abordagem Teológica da Hospitalidade Inter-Religiosa. 96 f. Dissertação (Mestrado em Teologia Sistemática). Faculdade de Teologia, Pontifícia Universidade Católica do Rio Grande do Sul, Porto Alegre.

The Way. (2010). [DVD] Directed by E. Estevez. USA: David Alexanian and Emilio Estevez. 